\title{
Trabalho, vida e morte no setor de rochas ornamentais: efeitos psicossociais do acidente de trabalho fatal para a família
}

\author{
Ana Beatryce Tedesco Moraes e Maria das Graças Barbosa Moulin \\ Programa de Pós-Graduação em Psicologia, Departamento de Psicologia Social e do Desenvolvimento, \\ Universidade Federal do Espírito Santo (Vitória, ES)
}

\begin{abstract}
Este estudo analisou os efeitos psicossociais dos acidentes de trabalho fatais, ocorridos em 2008, para as famílias das vítimas, no setor de mármore e granito, no estado do Espírito Santo. A pesquisa exploratória utilizou a entrevista semiestruturada como instrumento de coleta de dados, cuja análise seguiu o Método de Interpretação de Sentidos. Participaram da pesquisa oito famílias, identificadas a partir da Comunicação de Acidente de Trabalho. A percepção das famílias sobre o acidente de trabalho se mostrou associada às características da atividade no setor de rochas, como: condições de trabalho desfavoráveis à segurança, proximidade entre relações pessoais e profissionais e falta de informação sobre os acidentes. $\mathrm{O}$ acidente de trabalho fatal trouxe diversas implicações para todos os membros das famílias, como agravos à saúde, mudanças de comportamento e dificuldade em lidar com a ruptura dos planos. As formas de enfrentar a morte indicaram que a superação da perda foi viabilizada principalmente por familiares, amigos e religião. A maioria das empresas cumpriu suas obrigações legais com presteza, e o Poder Público foi evidenciado no que tange aos benefícios concedidos às famílias das vítimas, mas se mostrou ausente nas ações de transformação da organização do trabalho para prevenção de acidentes.
\end{abstract}

Palavras-chave: Acidentes fatais, Efeitos psicossociais, Setor de rochas, Saúde do trabalhador.

Work, life and death regarding the sector of ornamental rocks: psychosocial effects of fatal work accidents for the families

This study analyzed the psychosocial effects for the families of the victims of fatal work accidents occurred in the sector of marble and granite in 2008, in the state of Espírito Santo, Brazil. In the exploratory research, semistructured interviews were utilized as the means of collection of data, whose analysis followed the Method of Senses Interpretation. Eight families, identified through the Work Accidents Communication, participated in the research. The families' perceptions about the work accidents were associated to the characteristics of the activity in the rock sector, such as: work conditions unfavorable to safety, proximity between personal and professional relations and lack of information about accidents. The fatal work accidents brought several implications for all the family members, for instance, damage to health, behavioral changes and difficulty to deal with the break of plans. The manners of facing death indicated that the overcoming of losses was mainly enabled by family members, friends and religion. Most of the companies complied with all the legal obligations with promptitude. Government was highlighted regarding the benefits granted to families of the victims; however, it was absent in the transformational actions toward the organization of work in order to prevent accidents.

Keywords: Fatal accidents, Psychosocial effects, Sector of rocks, Worker's health.

\section{A saúde do trabalhador e os acidentes de trabalho}

A relação entre a saúde e o trabalho passou por diversas mudanças conceituais e práticas ocorridas historicamente. O processo de construção dessa relação foi descrito por Mendes e Dias (1991), que apontam as principais características da medicina do trabalho, da saúde ocupacional e da saúde do trabalhador. A medicina do trabalho surgiu no interior das fábricas, no século XIX, com a Revolução Industrial, onde o papel do médico estava a serviço do empregador e do capital, cujas atividades estavam voltadas para a manutenção da força de

1 Este trabalho foi baseado na dissertação de mestrado apresentada à Universidade Federal do Espírito Santo, em julho de 2011, por Ana Beatryce Tedesco Moraes, sob orientação da Professora Dra. Maria das Graças Barbosa Moulin. Apoio financeiro: Bolsa de Mestrado da Coordenação de Aperfeiçoamento de Pessoal de Nível Superior (CAPES). 
trabalho e do processo produtivo. Nesse contexto, os problemas relativos à saúde concentravam-se exclusivamente na figura do médico (Mendes \& Dias, 1991).

No período após a Segunda Guerra, a evolução da tecnologia industrial repercutiu em processos e produtos, acompanhados da insatisfação dos empregados e empregadores quanto aos agravos à saúde. "Entre muitos outros desdobramentos deste processo, desvela-se a relativa impotência da medicina do trabalho para intervir sobre os problemas de saúde causados pelo processo de produção" (Mendes \& Dias, 1991, p. 191). A saúde ocupacional emergiu nesse cenário como tentativa de resposta a essas questões, enfatizando a higiene industrial e objetivando o controle dos riscos presentes no ambiente de trabalho.

A saúde ocupacional também se tornou um modelo insuficiente diante de um cenário de movimento social nos países industrializados, nos anos 1960, a partir da introdução de novas tecnologias de comunicação e informatização, que se traduziram em outras formas de adoecimento associadas ao trabalho (sofrimento psíquico, LER/DORT, cânceres, problemas cardiovasculares). Conforme relatam Mendes e Dias (1991, p. 347), a saúde do trabalhador emerge como consequência dessas mudanças sociais e se configura como "um campo em construção no espaço da saúde pública", rompendo com a concepção hegemônica de causalidade entre doença e agente específico. Nessa perspectiva, o trabalhador é reconhecido como um sujeito histórico, dotado de subjetividade, de criatividade e de conhecimento da atividade que pratica.

Atualmente, as práticas relacionadas com a saúde ocupacional não foram sobrepostas pelo campo da saúde do trabalhador e estão em vigor até hoje no interior das empresas. De acordo com Minayo-Gomez e Thedim-Costa (1997), a saúde do trabalhador pode ser compreendida por

[...] um corpo de práticas teóricas interdisciplinares - técnicas, sociais, humanas - e interinstitucionais, desenvolvidas por diversos atores situados em lugares sociais distintos e informados por uma perspectiva comum. Essa perspectiva é resultante de todo um patrimônio acumulado no âmbito da Saúde Coletiva, com raízes no movimento da Medicina Social latino-americana e influenciado [sic] significativamente pela experiência italiana (p. 25).

A medicina social latino-americana, ilustrada pelos estudos de Laurell e Noriega (1989), critica a concepção de saúde da medicina tradicional em relação à coletividade, em que a saúde é entendida como ausência de doença. Essa abordagem preconiza a historicidade dos processos biopsíquicos humanos e compreende a saúde como processo social e histórico.

A análise do acidente de trabalho constitui-se um grande desafio ao campo da saúde do trabalhador, uma vez que sua prática tem sido pautada na medicina tradicional, em que o risco é entendido de forma monocausal, considerando somente as condições e os atos inseguros (Laurell \& Noriega, 1989). Em contraposição a esse modelo, Laurell e Noriega (1989, p. 110) propõem uma nova categoria para integrar os elementos presentes no trabalho, relacionada com o processo de saúde-doença, denominada "carga de trabalho".

Essa categoria permite entender como os elementos presentes no trabalho interatuam dinamicamente entre si e com o corpo do trabalhador, "gerando aqueles processos de adaptação que se traduzem em desgaste, entendido como perda da capacidade potencial e/ou efetiva corporal e psíquica". Nessa perspectiva, o acidente de trabalho é entendido a partir do processo de produção, e não como resultado de condição insegura e do ato inseguro. É analisado como "produto de uma combinação de cargas determinada pela lógica global do processo de trabalho" (Laurell \& Noriega, 1989, p. 114).

A despeito dos avanços em estudos sobre acidentes de trabalho, uma das formas de análise de acidentes que ainda persistem nas empresas brasileiras está ligada à Teoria dos 
Dominós, elaborada por Heinrich, na década de 1930, cujos conceitos centrais se baseiam no ato inseguro e na condição insegura, concepções estas que, em última instância, responsabilizam o próprio trabalhador pelos acidentes. Esses argumentos se sustentam com respaldo no processo de naturalização dos riscos, como se eles fizessem parte do processo de trabalho e fossem naturais e inevitáveis (Oliveira, 2007).

Freitas (2001) evidencia que o foco da análise do acidente deve ser modificado, pois, se o trabalhador for culpabilizado pelo acidente, suas causas não são sanadas, uma vez que estão relacionadas com o contexto social e organizacional. $\mathrm{O}$ autor aponta a necessidade de melhoria dos métodos de análise de acidentes, em que a realidade do trabalho deve ser revelada pela incorporação dos conhecimentos dos trabalhadores na investigação das suas causas subjacentes, já que os eventos finais que resultam em acidentes são frutos da acumulação de falhas organizacionais e gerenciais. $O$ processo de culpabilização dos trabalhadores, vítimas de acidentes pelas organizações, refere-se a uma tentativa de convencer que os riscos estão sob controle e manter a estabilidade das relações sociais de trabalho, conservando a estrutura de poder interno (Freitas, 2001).

O acidente de trabalho implica mudanças e perdas significativas não apenas no ambiente organizacional, mas também no andamento da organização familiar. Nesse sentido, é importante compreender a morte no que se refere ao seu processo histórico e à elaboração do luto para analisar os efeitos psicossociais de um acidente de trabalho.

\section{Entendendo a vida a partir da morte}

Diversos estudos analisam a morte a partir de circunstâncias vivenciadas pelo ser humano, como doenças ou perda de pessoas, buscando entender seu sentido a partir destas experiências. Kovács (1992) aborda a morte como parte do desenvolvimento humano, vivenciada em várias etapas da vida como falta, perda, ausência e limite, aspectos que vão além da morte biológica. O conceito de morte abordado por Torres (2002) retrata sua complexidade e indica os aspectos mais estudados pelos pesquisadores sobre esse tema:

Embora se observem diferenças na forma como os diversos pesquisadores enfocam o conceito de morte, alguns estudiosos [...] assinalaram a importância de que o mesmo seja investigado não como um conceito único, mas como um conceito complexo, multidimensional, que envolve subconceitos, sendo a universalidade, a não funcionalidade e a irreversibilidade as três componentes mais amplamente pesquisadas (p. 221).

De acordo com Kovács (1992, p. 153), as reações diante de uma perda são definidas como processo de luto e, durante seu período de elaboração, "podem ocorrer distúrbios na alimentação ou no sono. Um grande número de enlutados apresenta quadros somáticos e doenças graves depois do luto, podendo se configurar uma depressão reativa ou até um quadro mais grave".

Bowlby (1985), citado por Kovács (1992), descreve quatro fases do luto:

1. Fase de choque, que tem a duração de algumas horas ou semanas e pode vir acompanhada de manifestações de desespero ou de raiva; 2. Fase de desejo e busca da figura perdida, que pode durar também meses ou anos; 3. Fase de desorganização e desespero; 4. Fase de alguma organização (p. 151). 
O autor destaca que o processo de elaboração do luto depende de fatores relacionados à causa e à circunstância da perda, ao investimento afetivo depositado no vínculo e às características da personalidade da pessoa enlutada.

Aspectos ligados à cultura e ao momento histórico também interferem na forma de vivenciar uma perda, pois as atitudes diante da morte não se deram na mesma maneira ao longo dos tempos. Ariès (1989) descreve essas atitudes nos diferentes momentos históricos, mas lembra o caráter lento e pouco perceptível desse processo de mudança. Para o autor, "a morte domesticada" é caracterizada na primeira Idade Média, período em que as pessoas pressentiam a morte e havia grande valorização da preparação para esse momento, com rituais e organização para aguardá-la. $\mathrm{O}$ autor destaca que a morte se apresentava como algo simples e familiar, ligada a uma concepção coletiva de destino. Nesse período, existia uma relação de proximidade entre os espaços de convivência e as sepulturas; estas, por sua vez, eram localizadas no interior da igreja, e os cadáveres eram alojados em locais comuns.

O fenômeno da utilização das sepulturas para conservar a identidade e memória do morto se estabelece a partir do século XII, quando o reconhecimento de um lugar individual, definitivo e personalizado para os mortos se associava à ideia de individualidade. Esse período, denominado por Ariès (1989) como "a morte de si próprio", não substitui a atitude anterior, mas introduz sutis modificações a partir de novas atitudes que representam particularidades de cada indivíduo, como a ideia de prestação de contas no Juízo Final e a personalização das sepulturas. Nesse período,

[...] fez-se uma aproximação entre três categorias de representações mentais: as da morte, as do conhecimento por cada um da sua própria biografia e as do apego apaixonado às coisas e aos seres possuídos durante a vida. A morte converte-se no lugar onde o homem tomou melhor consciência de si mesmo (Ariès, 1989, p. 38).

A atitude perante a morte adquire conotação mais intensa a partir do século XVIII, enunciada por Ariès (1989) como "a morte do outro". Nesse período, a morte é considerada uma ruptura, uma transgressão, de modo que a intolerância à separação é acompanhada por sofrimento, exaltação emocional e vivência do luto de forma exacerbada. O ritual das cerimônias diante do leito do morto continua, mas apresenta algumas diferenças que caracterizam as atitudes desse período:

A morte no leito tinha noutros tempos a solenidade, mas também a banalidade, das cerimônias sazonais. A morte era aguardada e as pessoas entregavam-se então aos rituais previstos pelo costume. Ora, no séc. XIX, uma paixão nova se apodera dos presentes. A emoção agita-os, eles choram, rezam, gesticulam. Não recusam os gestos ditados pelo uso, bem pelo contrário, mas retiram-lhes o seu carácter banal e costumeiro (Ariès, 1989, p. 45).

A intolerância à morte do outro se mostrava presente no sentimento dos familiares relacionado com o fato de esconderem do doente a gravidade de seu estado, com a intenção de poupá-lo. Em determinado momento posterior, tal atitude foi recoberta por um sentimento

[...] característico da modernidade: evitar já não ao doente mas à sociedade e ao próprio círculo de relações, o incômodo e a emoção demasiado forte, insustentável, provocados pela fealdade da agonia e a simples presença da morte em plena vida feliz, pois se admite agora que a vida é sempre feliz ou deve parecê-lo sempre. Nada mudou ainda nos ritos da morte, que se conservam ao menos na aparência, e ninguém tem por enquanto a ideia de os alterar. Mas começou-se já a esvaziá-los da sua carga dramática; iniciou-se o processo de escamoteamento (Ariès, 1989, p. 56).

A discrição das manifestações e do luto diante da morte caracteriza, segundo Ariès 
(1989), “a morte interdita”, período no qual "o luto deixa de ser, portanto, um tempo necessário cujo respeito a sociedade impõe; tornou-se um estado mórbido que é preciso tratar, abreviar, eliminar" (p. 62). As mudanças de atitude diante da morte, como a contenção das emoções, foram propiciadas pelo fenômeno de transferência do local da morte, que outrora era em casa e passa a ser no hospital, local agora destinado não só a curar, mas também a morrer.

Como foi possível observar, a morte traz implicações psicológicas e sociais associadas às características pessoais, e também ao período histórico e à cultura. Estabelece-se aqui um desafio relacionado à compreensão da morte em uma atividade valorizada socialmente, como o trabalho.

Levando em consideração esses aspectos, o presente estudo pretendeu dar visibilidade às consequências da morte no trabalho e se constitui também uma tentativa de preencher lacunas e produzir novas questões para o estudo nessa área. Pretende-se, em particular, dar maior visibilidade aos efeitos psicossociais dos acidentes de trabalho fatais para as famílias das vítimas e entender como elas se reorganizaram após o acidente fatal. Como pano de fundo, está presente a ideia de contribuir para a desnaturalização dos acidentes de trabalho como inerentes à atividade. Só assim entende-se ser possível transformar a organização do trabalho em promotora de vida e saúde.

\section{Metodologia}

Este estudo analisou como acidentes de trabalho fatais, ocorridos em 2008, no setor de mármore e granito, no estado do Espírito Santo, afetaram psicossocialmente as famílias das vítimas, na tentativa de responder a diversas indagações: $\mathrm{O}$ que mudou na vida das famílias após a ocorrência do acidente? Como elas se reorganizaram dos pontos de vista social, econômico, simbólico e afetivo? Como superaram a fatalidade? Que recursos materiais e subjetivos utilizaram? A apreensão desses fatos foi feita por meio da pesquisa qualitativa de cunho exploratório, pois pretendeu dar maior visibilidade ao objeto investigado, que ainda é pouco estudado.

Em função de sua finalidade e organização, utilizou-se a entrevista semiestruturada. As entrevistas tiveram características de uma conversa, mas com propósitos bem definidos pelo pesquisador, como forma de obter informações construídas no diálogo com as famílias (Minayo, 2007).

O levantamento das famílias das vítimas de acidente de trabalho foi realizado por meio da Comunicação de Acidente de Trabalho (CAT), disponibilizada pelo Sindicato dos Trabalhadores em Indústria de Extração e Beneficiamento do Mármore, Granito e Calcário do Espírito Santo (Sindimármore). Dez famílias foram identificadas pelas CATs, mas apenas oito foram entrevistadas, pois uma esposa não quis participar da pesquisa, e a outra família havia se mudado do Espírito Santo. Entre as famílias entrevistadas, três residiam no município de Cachoeiro de Itapemirim e duas em Vargem Alta; as demais eram de Castelo, Guarapari e Venda Nova do Imigrante. O tempo decorrido entre os acidentes e a realização das entrevistas variou de 13 a 24 meses.

As entrevistas foram individuais, mas, como estavam sujeitas às relações existentes na dinâmica familiar, em duas entrevistas houve participação de mais de um integrante da família (uma entrevista foi concedida pela mãe com participação do pai da vítima, e outra, pela mãe com participação da irmã da vítima). As demais entrevistas foram concedidas pelas esposas das vítimas. Para facilitar a identificação das famílias, nos resultados e na discussão, elas serão 
apresentadas pela letra "F", seguida de uma numeração, que corresponde à ordem em que as entrevistas ocorreram.

Todas as entrevistas foram gravadas e transcritas integralmente. A análise e a interpretação dos dados seguiram o Método de Interpretação de Sentidos, que, de acordo com Gomes (2007, p. 82), "trata de uma proposta ancorada em obras clássicas do campo da pesquisa qualitativa". $\mathrm{O}$ autor descreve três etapas que compõem esse método de interpretação. $\mathrm{O}$ objetivo da primeira é ter uma visão de conjunto a partir da leitura compreensiva do material selecionado e apreender as particularidades do material. $O$ segundo passo refere-se à exploração deste material, quando o pesquisador deve ser capaz de ir além das falas e dos fatos, no sentido de chegar ao que está implícito e velado, decompondo o material em unidades. A última etapa aproxima-se de uma síntese, possibilitada pelo trabalho "com sentidos mais amplos, que traduzem a lógica do conjunto do material. Para que tenhamos êxito nessa síntese interpretativa, devemos, principalmente, fazer uma articulação entre os objetivos do estudo, a base teórica adotada e os dados empíricos" (Gomes, 2007, p. 101).

\section{Resultados e discussão}

Para analisar os efeitos psicossociais do acidente de trabalho fatal para as famílias, foi imprescindível compreender algumas características do setor de rochas que emergiram nas entrevistas. A investigação dessas características se mostrou fundamental para entender o que o trabalho representa dos pontos de vista social e psicológico para o grupo pesquisado, e como o acidente de trabalho fatal é vivenciado, como fruto dessa atividade.

O cenário que se descortinou sobre as características identificadas a partir das entrevistas mostrou condições de trabalho desfavoráveis à segurança, como máquinas quebradas e sem freio e falta de equipamentos de segurança. Todas as famílias entrevistadas relataram a ocorrência de diversos acidentes no setor, como se fizessem parte da rotina das empresas. Todos tinham um "caso" pra contar, com a própria vítima, antes de sua morte, ou com outros trabalhadores da mesma empresa. As famílias não fizeram correlação entre esses elementos e o acidente fatal, mas se entende que os acidentes anteriores à fatalidade são "pistas" de que algo mais grave, cedo ou tarde, poderia acontecer, pois dão sinais de que alguma coisa não vai bem no trabalho. Observa-se que essa falta de correlação está associada à percepção das famílias de que os riscos são inerentes ao trabalho, como se a aceitação dessa condição desfavorável à segurança fosse em prol da garantia da permanência no emprego, conforme relato:

Ele falou: "A máquina tá sem freio e tem que consertar". Inclusive, antes, o encarregado da firma era meu cunhado, né? [...] Ele não deixava a máquina ir pra um lugar perigoso, porque ele sabia do perigo [...]. Aí, depois que meu cunhado saiu, que veio um outro encarregado, que começou a mandar, né? Aí, se não fosse, mandava embora e ele, já viu, né? Tinha que trabalhar (F6).

Esse contexto cultural e social faz as famílias perceberem e conviverem com os riscos presentes no setor de rochas em função de sua inserção no trabalho, garantindo a sobrevivência material e simbólica.

Foi possível observar nas entrevistas que os trabalhadores e suas famílias mantinham com os patrões um tipo de relação que comumente extrapolava a convivência no ambiente de trabalho. Esse fenômeno ocorria não só pela grande quantidade de membros das famílias dos empregados no setor de mármore e granito, mas também pela existência de parentesco entre a vítima e o patrão, além das relações afetivas estabelecidas entre as famílias e os donos das 
empresas, como mostra o relato: "Aí, eu não tenho como ficar sentida com nada, que o patrão dele, que é tão honrado, tão amigo nosso, que ele sofreu, sofre muito. Ele me toma bênção agora, ele me chama até de mãe tem hora" (F3). A proximidade observada entre as relações pessoais e profissionais pode ser propiciada pelo fato de o setor de rochas ser a principal fonte de trabalho na região, restringindo as oportunidades de trabalho às atividades de extração e beneficiamento do mármore e granito. Em pesquisa realizada com trabalhadores sindicalizados do setor de rochas em Itaoca, no sul do Espírito Santo, Baptistini (2009, p. 138) constatou que "todos os residentes do distrito [de Itaoca] têm, de alguma forma, uma ligação com o setor", uma vez que a atividade de extração de rochas é a principal atividade econômica do município.

Essa proximidade entre a vida pessoal e profissional pode ter interferido na percepção que as famílias das vítimas tinham sobre os acidentes de trabalho e sobre a responsabilidade das empresas sobre eles, principalmente quando se estabelecia uma relação afetiva entre a família e o dono da empresa. No estudo de Moulin realizado em Itaoca (2006), também ficou evidente esse fenômeno - que a autora nomeou de relações de compadrio -, que, na ocorrência de infortúnio, desvelava para a família tratar-se de uma relação de trabalho, em uma atividade tão perigosa, que o trabalhador chegou a morrer.

Outro aspecto recorrente nas entrevistas foi a falta de informação sobre o acidente fatal. Em geral, a notícia do acidente chegou às famílias por conhecidos ou colegas de trabalho da vítima, mas os motivos que o ocasionaram não eram claros. A constatação de que as famílias não tinham informações sobre os acidentes no setor de rochas também foi feita por Moulin (2006), ao entrevistar diferentes atores sociais, como aposentados, vítimas de acidentes, viúvas e membros do sindicato. De acordo com a autora, "a culpabilização apressada do trabalhador, sem sequer analisar quaisquer outros elementos envolvidos no evento, foi e é ainda uma forma eficaz de perpetuação dos acidentes" (Moulin, 2006, p. 63).

Embora algumas famílias tivessem mais elementos sobre a causa do acidente de trabalho, o fato que prevaleceu nas entrevistas realizadas foi a falta de informação sobre sua ocorrência. A partir do levantamento dos acidentes para realização desta pesquisa, constatouse que não são apenas as famílias que estão desprovidas dessas informações, mas também os órgãos públicos responsáveis pela elaboração e pela emissão de registros de acidentes de trabalho, o que remete à questão da falta absoluta de investigação sobre os acidentes de trabalho no setor.

Entendemos que a investigação apropriada do acidente, com especial atenção às condições de trabalho, pode ser um elemento para questionar um processo de trabalho que vitima duplamente os trabalhadores: quando ele se acidenta e quando é culpabilizado pelo acidente que sofreu. No entanto, as famílias ainda enunciam esses infortúnios como fatalidades, em que o questionamento não está previsto. Ao contrário, trata-se de algo sobre o que, por vezes, não se quer falar. Conhecer a visão das famílias sobre o acidente de trabalho fatal possibilitou a constatação da falta de informação sobre suas causas - ou falta de desejo por informação, o que impede a transformação na organização do trabalho e leva à perpetuação de acidentes. Embora a investigação do acidente fatal não tenha sido uma questão para os entrevistados, ela se coloca para o pesquisador como tal. Trata-se de uma das contribuições deste estudo: insistir em fazer falar algo que o senso comum, por razóes diversas, insiste em calar.

Os efeitos psicossociais do acidente de trabalho foram analisados separadamente - por uma questão didática -, sob a perspectiva dos filhos, das esposas e da família ampliada. Posteriormente, foram analisadas as formas de suporte social e de superação relacionadas às famílias das vítimas de acidentes de trabalho. 


\section{A repercussão para os filhos}

Os efeitos do acidente de trabalho fatal observados pelas famílias em relação aos filhos foram: diminuição do desempenho escolar, interferência na saúde e, principalmente, mudanças no comportamento. Os problemas relacionados ao desempenho escolar foram observados com todos os filhos de uma família:

E com isso, esse ano todos os três [filhos] foram péssimos na escola. [...] $O$ de 11 anos ficou reprovado. Não teve jeito, eu tentei, fui a psicólogo [...]. E o de 14 quase perdeu o ano também, e nunca tirou uma nota vermelha, era um menino excelente na escola. Esse ano, ele deu esse trabalho, ele assim, ficou distraído. Enfim, tudo prejudica, né? Não tem nada que não prejudicou (F6).

O discurso desta mãe introduz um elemento à dinâmica de reorganização emocional da família, que é a possibilidade (ou não) do recurso às técnicas psicoterápicas. A busca pelo serviço psicológico relatada por esta e outras esposas entrevistadas não se mostrou uma escolha espontânea das famílias, mas aconteceu por incentivo da empresa ou da escola - alguém de fora da intimidade do grupo familiar - que comunga desse tipo de recurso direcionado para o âmbito individual. Sobre este aspecto, Kovács (1992, p. 164) acredita "que o trabalho psicoterápico, embora não obrigatório, [...] pode auxiliar enormemente no processo de luto".

De acordo com Baptistini (2009, p. 116), no distrito de Itaoca, há apenas "uma unidade do Programa de Saúde da Família (PSF) e um Pronto Atendimento (PA)". Levando em consideração esse fato e os relatos das famílias entrevistadas sobre o custo da psicoterapia, conclui-se que os serviços de psicologia ofertados pela rede pública são restritos, quando não ausentes. Tais informações indicam que as famílias têm acesso à psicoterapia por meio da consulta particular: "Inclusive eu tive muito problema com meu filho o ano passado no colégio, meu filho mais novo. Inclusive, a professora pediu que eu levasse num psicólogo, mas não tive como levá-lo, que é muito difícil, você não consegue levar pelo SUS, particular é muito caro, então não consegui" (F7).

O fato de algumas famílias não buscarem o profissional de psicologia pode estar relacionado não apenas à falta de recurso material, mas também à questão simbólica, pois, como mostrou o estudo de Moulin (2006), trata-se de uma cultura cujos recursos de superação advêm do coletivo, como religião, vizinhança e família.

Em relação aos efeitos na saúde dos filhos, estes foram relatados pelas famílias juntamente com mudanças no comportamento associadas a tristeza e sofrimento, como foi o caso de dois irmãos: "A pequenininha, a de três aninhos na época, [...] ela ficou doente, ela não comia. Durante um mês, ela emagreceu, ela perdeu peso, sentindo muito, chorava muito, queria o pai, ela sofreu muito. [...] Agora o do meio, o de 11 anos [...], ele ficou passando mal vários meses [...]" (F6).

Tais efeitos também foram observados a partir das mudanças de comportamento descritas, como agressividade, rebeldia e revolta, como conta uma esposa: "Ele ficou uma criança mais agressiva, igual na escola. Ele falava que ninguém aqui em casa gostava dele, que quem gostava aqui era o pai dele e o pai dele morreu. [...] tudo que a gente fala com ele, se não for do gosto dele, ele fica irritado, brigando, sabe?" (F7).

Algumas crianças apresentaram outro tipo de comportamento, pois se tornaram mais retraídas e caladas, conforme relato de uma esposa: "Eu não sei explicar, porque ela se fechou. Ela se fechou pro mundo, pras amizades. Eu até, num certo momento, eu não percebi que ela tava sentindo muito, porque criança, todo mundo acha assim: criança não sente, né?” (F2). Kovács (1992, p. 157), referenciando o estudo de Bowlby (1979), relata que "a criança passa pelas mesmas fases de luto que o adulto, desde que esteja de posse dos esclarecimentos de que necessita e que 
devem ser fornecidos, levando-se em conta o seu nível cognitivo e capacidade de compreensão".

\section{As rupturas vivenciadas pelas esposas}

Os efeitos psicossociais do acidente de trabalho fatal para as esposas versaram sobre a saúde, a saudade e a ruptura dos planos. As mudanças ocorridas após o acidente fatal provocaram destruição de sonhos e interrupção das formas de viver, evidenciando as rupturas relacionadas com os aspectos afetivos e psicológicos. Uma das entrevistadas relatou: "No ano passado, eu ia começar [...] a fazer o estágio e começar o trabalho, aí aconteceu isso tudo, eu parei, minha vida parou" (F2). Em outros relatos, as consequências, na esfera afetiva, evidenciam-se pela destruição de um sonho: "Nossa, ele era lindo. Então, assim, ele jogava bola, ele tava vivendo assim, o auge da vida dele, então foi um choque assim, que tirou, acabou o sonho, né?" (F6).

O estudo de Moulin (2006, p. 116) mostrou que, aos poucos, as famílias entrevistadas conseguiram se recuperar "do ponto de vista material, simbólico, social e afetivo". Na presente pesquisa, a reestruturação foi observada apenas com relação à questão financeira, o que faz supor que as entrevistas foram realizadas num período ainda recente em relação à morte das vítimas fatais. Tal suposição pode ser evidenciada pelo relato de uma esposa sobre a falta do marido no cotidiano:

Ah, mudou tudo, né? Porque ele era meu companheiro, a pessoa que eu convivi 29 anos, casada. [...] Então eu sinto muita falta dele, né? Porque eu perdi minha mãe, eu tinha dez anos então eu não tive infância, não tive juventude. Eu comecei a viver, eu sempre falo, eu comecei a viver depois que eu casei, entendeu? Que eu não tenho um pingo de saudade da minha vida solteira, então ele foi tudo. Eu perdi tudo (F5).

Entre os efeitos na saúde das esposas, os mais significativos foram o emagrecimento brusco, a depressão e o uso de remédios, como se pode verificar no relato: "Bom, eu perdi dez quilos, estou dormindo a poder de remédio. Até hoje. [...] comecei a perder cabelo" (F2). Outra esposa também percebeu agravos a sua saúde e relata, entre outros sintomas, a hipertensão. Ela acredita que seja em função do seu estado emocional, já que não tinha problemas dessa natureza antes da morte do marido.

A depressão foi referida como consequência do acidente do marido na saúde de duas esposas, conforme relato de uma delas: "Eu trabalho. Eu sou servente num colégio. Trabalho pela Prefeitura, fui concursada pela Prefeitura, trabalho. Fiquei uns tempos afastada, né? Por causa, tive que fazer duas cirurgias e num sei também, fiquei muito depressiva, não tinha como eu trabalhar. Não aguentava trabalhar" (F5).

A partir das entrevistas, não foi possível identificar se a depressão relatada por ambas as esposas foi diagnosticada por um profissional de saúde ou se, simplesmente, elas se apropriaram desse nome comumente usado pelo senso comum para exprimir a tristeza e o desânimo adiante da perda dos respectivos maridos. De qualquer forma, optou-se por registrar esse efeito relatado pelas famílias como consequência dos acidentes fatais. 


\section{Os efeitos para a família extensa}

Os entrevistados relataram os efeitos do acidente para a família extensa - entendida aqui como a família além da nuclear, como avós, tios e cunhados -, conforme conta uma esposa: "[...] pra minha família foi um impacto muito grande também, porque, ele era uma pessoa muito querida, entendeu? Todo mundo gostava dele" (F7). Outra esposa relata a reação do irmão da vítima ao saber do acidente:

Olha, o irmão dele ficou revoltado, tanto é que, quando ele ficou sabendo da morte, ele cercou o encarregado. [...] e ele foi lá tirar satisfação: "Não, eu avisei você, pra nunca deixar a máquina assim, que ia acabar matando alguém. Quem que se machucou naquela pedreira?". Perguntou ele, mas ele sabia que era o irmão, né? Aconteceu com o irmão, né? Ele entrou em choque. A família ficou toda assim, né?" (F6).

Foram observadas mudanças nos relacionamentos entre as esposas e a família de origem da vítima. Em um dos casos, o relacionamento melhorou após o acidente: "Parece que, depois que ele morreu, parece que a família dele trata a gente melhor [...] quando a gente vai lá, eles conversam com a gente, assim, não igual antes, conversa talvez até melhor de que antes, lembra muito dele, né?" (F1). Já outra esposa conta que os familiares do marido acabaram se afastando dela após o acidente fatal, pelo fato de terem superado a perda com mais facilidade do que ela e, por esse motivo, não a compreendiam: "Até porque a minha dor eles não aceitavam, assim. [...] eles aceitaram depressa, eles queriam que eu também aceitasse, entendeu? Achavam, assim, exagero da minha parte. Então houve aquele afastamento e depois disso, eu procurei ficar mais no meu canto, e eles, mais no canto deles" (F2).

Os momentos vividos em família, como as datas comemorativas, foram relatados como os mais difíceis de serem superados após o acidente: "Olha, foi dois dias antes do Natal. Falo que Natal, pra gente, acabou, né? Natal acabou. Eu falei que Natal agora é como se fosse um qualquer dia de mês, não tem mais a graça" (F6). Outra família também relatou que as datas comemorativas perderam o sentido, além da dificuldade dos filhos em vivenciar momentos em família e de lazer:

Se você vai fazer alguma coisa, tá faltando alguém, vai sair, é o final de ano, é Natal, essas coisas, os meus filhos já não têm mais aquele prazer, tá entendendo? Pra eles, tanto faz, pra eles não existe Natal, não existe final de ano. Até sai, passeia, mas assim, aquele tipo: não quer enturmar com a família dele, nem com a minha pra poder não lembrar (F4).

Uma esposa observou mudanças na saúde do sogro após o acidente: "[...] o pai dele tá doente, o pai dele fica variando, falando que ele vai voltar" (F4). Outro relato também aponta os efeitos do acidente para o irmão da vítima, que, conforme a mãe, "ficou em tempo de ficar doido" (F8), referindo-se ao fato de ele ter ficado "desorientado" e nervoso, pois trabalhava junto com o irmão e presenciou sua morte, não se conformando com o fato.

\section{Suporte social}

Neste estudo, entende-se como suporte social elementos que ajudaram na reorganização da família, no que tange às obrigações legais e aos setores públicos. A reorganização familiar, do ponto de vista econômico, após a ocorrência do acidente fatal, foi propiciada em grande parte pelas indenizações e pensões, viabilizadas pela empresa ou pelo sindicato. As famílias entrevistadas foram assistidas pelas empresas, que se mostraram 
preocupadas em oferecer suporte ao que fosse necessário e mantinham contato frequente com os familiares das vítimas. Embora os entrevistados tenham reconhecido o apoio das empresas, quando descreveram o tipo de ajuda oferecida, observou-se que esta estava, na maioria das vezes, restrita aos direitos legais das vítimas: "Ajudaram muito [empresa]. Ajudaram. Com o dinheiro da indenização, a mãe comprou essa casa aqui. O outro restante, a mamãe comprou alguma coisinha pra ela e pagou o advogado" (F8).

Os relatos indicaram que as empresas agilizaram o processo burocrático com o intuito de que as famílias fossem beneficiadas com: pensão do INSS, seguro de vida, pagamento pelo tempo de serviço e, em alguns casos, indenização. Há diversos relatos sobre os esforços empreendidos pelas empresas para "correr atrás da burocracia" para conseguir tais direitos: "Eu tive muito apoio dos patrões dele, né? Me apoiaram bastante pra tá providenciando documentação, coisas do seguro, precisa de muita documentação" (F2).

Uma esposa relatou ajuda da empresa associada aos direitos legais: "Tanto que me ajudou, a gente fez um acordo. Eu sou pensionista hoje, eu recebo, por causa dessa firma que entrou na época, tudo direitinho [...] a gente foi no advogado, tá pagando direitinho, tudo certinho. Eu não tenho nada a reclamar" (F4). De acordo com outra esposa, logo que o marido faleceu, a empresa entrava em contato com frequência, mas foi possível observar que, em geral, tais contatos versavam sobre questões legais: "Eles [empresa] me chamavam lá quase sempre assim, no começo. [...] Eles só me chamavam lá mesmo quando tava dando algum problema, alguma coisa assim, igual no seguro de vida dele, precisava de mais alguma coisa" (F1). Esse relato dá indícios de que a empresa se fazia presente para tratar de assuntos burocráticos, mas, à medida que eles iam sendo resolvidos, o contato diminuía.

Além do suporte relacionado aos direitos trabalhistas cumpridos pela maioria das empresas, observou-se que existia preocupação de alguma delas com as consequências psicológicas do acidente. Uma empresa sugeriu tratamento psicológico para a esposa e a filha da vítima e arcou com as despesas: "Então eles me ajudaram bastante. Até hoje, eles pagam o psicólogo da gente. Eles pagam até hoje. Eles dão bastante assistência. Me procuram, de vez em quando eles ligam, vêm aqui pra saber como a gente tá" (F2).

A realidade abordada pelo grupo pesquisado mostrou que, em alguns casos, a ajuda das empresas foi além da questão financeira, pois o fato de as famílias "sentirem" que podiam contar com elas propiciou também conforto psicológico. Essa realidade contrasta com dados de Moulin (2006, p. 108), já que, em todas as entrevistas realizadas pela autora, houve reclamações sobre o patrão após a ocorrência do acidente de trabalho, a partir das quais a autora verificou que "a reação dos empresários deslizou entre a omissão e a irresponsabilidade". A reação da família em face da conduta da empresa, embora pareça antagônica a princípio, revela-se como os lados da mesma moeda, ou seja, a presente pesquisa evidenciou que as famílias entrevistadas ficaram satisfeitas por terem sido "amparadas" pela empresa. Já no trabalho de Moulin (2006), as famílias mostraram-se "indignadas" porque foram destratadas pelos empresários. A partir dessas duas pesquisas, configura-se a ideia de que se trata de uma questão relacional - entre patrão, empregado e família -, e não de direitos ou contrato de trabalho regido por lei.

Ao se pensar no trabalhador apenas como provedor material das famílias entrevistadas, não houve alterações significativas na renda familiar, como conta uma esposa: "Olha, eu entrei na Justiça junto com o sindicato, entrou na Justiça contra a firma, né? Pedindo a indenização e eu ganhei. [...] Então assim, em matéria financeira, nós ficamos bem amparados, a gente não tem o que reclamar, não" (F6). Observou-se que as famílias não perceberam mudanças em relação à questão financeira em função de terem recebido as indenizações e os benefícios após o acidente.

O Poder Público foi mencionado de forma indireta nos relatos das famílias, no que se referia aos benefícios recebidos, mas se percebe que não era atuante sob o ponto de vista do 
atendimento das vítimas de acidentes de trabalho, da fiscalização e de políticas públicas para o setor. Apenas uma família relatou que o Ministério do Trabalho multou a empresa em que a vítima trabalhava em função das condições de trabalho, mas antes da ocorrência do acidente fatal. Se, por um lado, o Poder Público pareceu ausente na realidade da maioria das famílias, por outro, viabilizou que elas se reorganizassem economicamente - via benefícios concedidos -, propiciando que dessem início à reorganização de outros aspectos, o que mostra a importância do vínculo de trabalho formal em um mundo de trabalho cada vez mais precário.

Duas famílias entrevistadas relataram que as empresas não cumpriram seus deveres legais, o que não ocorreu com as demais que, prontamente, se preocuparam com esse auxílio. Em uma delas, o dono era irmão da vítima e, inclusive, descontou as despesas do funeral do irmão do acerto pelo tempo de trabalho ao qual a esposa tinha direito: "[...] daí um mês eu comecei a receber a pensão, mas a indenização, não. Eu deixei quieto, porque eu achei que ele ia me dar mais apoio, né? [...]. Ele nunca me perguntou se tava faltando alguma coisa, se eu tava precisando de alguma coisa" (F5).

O Sindimármore foi citado espontaneamente apenas por essas duas famílias, o que pode evidenciar que as famílias só buscam o sindicato quando não recebem apoio das empresas, como foi o caso dessas famílias, conforme uma delas relata: "[...] eu gostei muito da visita dele [membro do sindicato], então, assim, eu vi que eu tinha alguém que queria me ajudar, né? Porque, se depender de patrão de firma, eu tenho certeza que eles não fizeram nada pra me ajudar de imediato" (F6).

\section{As formas de superação}

As formas de superação referem-se a elementos de apoio relacionados a características culturais, sociais e individuais. Entre os elementos que auxiliaram no processo de superação em diante da perda provocada por acidente de trabalho fatal, os mais frequentes foram a família e os amigos, seguidos da religião. $O$ trabalho, o estudo e a psicoterapia também foram mencionados pelas famílias como apoios presentes no processo de luto, mas de forma isolada.

Os entrevistados sentiram-se muito reconfortados pelos parentes, motivo pelo qual a família emergiu em quase todos os relatos como importante elemento no processo de superação, conforme conta uma esposa:

A minha família sempre procura não me deixar muito sozinha. Quando eu estou muito aqui, eles vêm, ai minha mãe me leva pra casa dela, eu fico assim, fim de semana todo com ela. Só fico em casa de segunda a sexta, sábado e domingo eu fico com ela, mesmo morando perto. Aí, hoje, por isso que eu consigo falar mais (F2).

Os filhos aparecem como fonte de significado para continuar vivendo, como mostrou o relato: "O que me fez ficar de pé foi meus filhos, lutar" (F6). Outra esposa também falou que encontrou força nos filhos para superar a morte do marido:

Então, eu busco força nos meus filhos, pra tentar lidar com isso. Só que é igual eu te falei, eu queria que, eu preferia que isso não acontecesse mais, porque, do mesmo jeito que eu sofro, eu não queria que outras pessoas sofressem por causa disso, entendeu? Por que quantas crianças mais ainda vai ter que ficar órfãos de pai pra essa firma tomar providência? (F7).

As famílias entrevistadas também enfatizaram o apoio recebido pelos amigos, principalmente nos momentos vivenciados logo após a fatalidade, como conta uma esposa: "Visitas aqui direto, toda tarde. Os amigos dele vinham toda tarde e muita gente, os vizinhos, telefone, 
pessoas que a gente nem pensava [...]" (F3). Os colegas de trabalho das vítimas se mostraram solidários com a família, sendo lembrados como fontes de apoio no processo de superação, conforme relato: "E ele tinha muito amigo, e, nessas horas, foi muito bom os amigos dele. Mas isso é o quê, né? É erguer a cabeça e continuar, né? Mas que uma morte assim choca a gente, choca, nossa!" (F6).

Os vizinhos - entendidos como amigos - foram citados por duas famílias como suporte no processo de superação: "Ó, teve meus vizinhos aqui que me apoiaram. Estava uma vizinha minha até na semana passada. Ela foi embora pro Rio. Ela me dava muita força, meus vizinhos aqui vinham aqui sempre pra conversar comigo" (F5).

Outro elemento que fez parte do processo de superação foi a religião, mencionada como fonte de conforto obtido pela fé e pelas orações: "Mas ele também tá me dando força, Deus. Eu acho que age na nossa vida, né? Acho não, com certeza" (F5). Uma esposa conta que sua participação na Igreja foi uma ajuda importante: "E também sou uma pessoa, assim, muito católica, muito temente a Deus. [...] procuro sempre estar na Igreja. Eu entrei no trabalho da Pastoral da Criança, fiquei como a coordenadora. Então são coisas assim que têm me ajudado bastante" (F2).

Observou-se que a religião apareceu como elemento que ajudou a suportar a morte com mais facilidade, que, por vezes, se traduziu em aceitação desse fato, conforme relato:

[...] só coloquei assim, que Jesus fizesse o melhor pra ele [vítima]. Falei: "Eu vou aguentar o que vier pra mim eu tenho certeza". E, colocando assim, que a gente tem um filho todo espatifado, também eu sei que aquilo é muito forte, né? E coloquei assim. A gente tá assim, a gente vendo outras coisas piores, que a gente vê, isso me dá força. Continuei indo a velórios, levando conforto e trazendo pra mim (F3).

O tom conformista quanto ao acidente de trabalho apresentou-se como uma forma de lidar com o sofrimento diante da perda, ancorado na recorrência e na naturalização de acidentes no setor. Tal aceitação está relacionada também ao fato de as famílias não quererem falar sobre o acidente, não quererem saber informações sobre sua ocorrência e não se indignarem pela forma como ocorreu. Como mencionou essa família, o fato de ver "coisas piores" - como outros acidentes fatais ou mutilações graves - "dá forças".

Se, por um lado, a resignação diante do acidente de trabalho se apresenta como uma forma de superar a perda, por outro, impede que o acidente de trabalho se torne um evento questionável pela sociedade. No relato citado, a indignação existe, mas fica restrita à perda do marido e não abrange a contradição presente no trabalho.

Na pesquisa de Moulin (2006, p. 103), os meios de superação estavam ancorados na religião, na família e na comunidade, elementos comuns aos identificados na presente pesquisa. Conforme a autora, "além de Deus, a rede de familiares, amigos e vizinhos foram fonte de ajudas materiais, espirituais e afetivas para suportar e para enfrentar as consequências do acidente". Mas, além desses elementos associados ao apoio coletivo, novos recursos emergiram no processo de superação das famílias na presente pesquisa. São eles: o trabalho, o estudo e a psicoterapia.

O trabalho formal foi citado por uma esposa - a única que não tinha filhos - como forma de superar a ausência do marido: "Olha, o que mais ajuda assim a ir superando é o serviço. Sai pra ir ao serviço, volta, assim. Lá tem um menininho que eu tomo conta dele, brinco com ele" (F1).

Duas esposas mencionaram a realização de trabalhos manuais como sinal da melhora no processo de superação da perda, como conta uma delas: "[...] até meus trabalhos artesanais que eu faço crochê, tricô, essas coisas assim - eu abandonei. Agora eu já comecei a voltar a mexer com essas coisas. Então, foi isso que me ajudou bastante" (F2). 
A psicoterapia também foi citada por essa esposa como ajuda para superar a morte do marido: "[...] foi uma coisa que derrubou muito mesmo, me botou bem pra baixo, agora que eu consigo falar no assunto, depois de acompanhamento de psicólogo, eu consigo conversar. Mas, antes, eu nem, não gostava nem de tocar no assunto" (F2). Como já abordado, a presença de profissionais, como pedagogos e psicólogos, foi relatada por três famílias como recurso utilizado para auxiliar no processo de superação dos filhos, relacionado principalmente ao desempenho escolar.

Outra esposa encontrou nos estudos nova possibilidade de inserção social que auxiliou em seu processo de superação:

[...] o que me ajudou mais foi o fato de estudar [...]. Agora eu terminei a oitava série, com isso foi maravilhoso, né? [...]. Então o fato de eu ir lá, e lá eu conheci muita gente diferente, coisas diferentes, passa a ter vários conhecimentos, com isso a mente da gente abre. Então é lá na escola que eu me reencontrava. Aqui eu era mãe, lá não, lá eu me reencontrava, então isso fez muito bem, o fato de eu estar estudando (F6).

Mesmo entendendo que o sindicato tenha função de suporte social, destacamos o relato de uma esposa que o citou como elemento do processo de superação: "[...] então eu fui muito bem amparada por eles [sindicato], lá, né? Até hoje, eu continuo indo lá, porque isso me ajudou muito a superar" (F6).

Entre as famílias entrevistadas, duas deram indícios de que superaram com mais facilidade a perda. Uma esposa (F1) não cita grandes mudanças após o acidente do ponto de vista financeiro, na saúde, na vida afetiva e relacional, embora relate a falta que sente do marido. Outra família conta que "não mudou praticamente quase nada. Quando ele era vivo, a gente era assim, depois que ele morreu, continuou a mesma coisa. [...] Aí, depois de 15 dias, voltou tudo ao normal" (F8). Levando em consideração as observações do pesquisador, a entrevista dessa família diferiu drasticamente das demais. Primeiro, em razão do pouco interesse que a família demonstrou sobre a pesquisa e, principalmente, devido ao pouco impacto da morte demonstrado pela família. Os relatos da mãe da vítima foram muito fragmentados e confusos, e, na maior parte da entrevista, foram complementados por sua filha.

\section{Considerações finais}

Estudar os efeitos psicossociais do acidente de trabalho fatal para a família da vítima mostrou que sua ocorrência não estava restrita ao mundo do trabalho, pois trouxe implicações para os filhos, esposas e a família extensa. Para os filhos, a perda do pai refletiu em agravos à saúde e em problemas no desempenho escolar. As mães também observaram mudanças no comportamento dos filhos, como: revolta, rebeldia, agressividade, retraimento, tristeza e sofrimento. As esposas sofreram efeitos associados à saúde, mas a maior dificuldade foi lidar com a ruptura dos sonhos e vivenciar o dia a dia na ausência do marido. Os efeitos, para a família extensa, ficaram mais evidentes nas datas comemorativas e nos momentos vivenciados em família, quando a ausência da vítima fez que as comemorações perdessem seu sentido.

A questão fundamental desta análise está pautada na interpretação de que as famílias entrevistadas percebem os riscos presentes no setor de rochas como parte do trabalho, pois, em se tratando de processo de elaboração do luto, não há diferenças significativas quando se compara com o luto vivenciado pela perda por outros motivos. Ou seja, não existem diferenças significativas quanto a efeitos na saúde, nos comportamentos e nas relações sociais das famílias quando a morte ocorre no trabalho. Destaca-se que as diferenças entre a morte no trabalho e a 
causada por outro motivo foram justamente as características do setor de rochas, a naturalização dos riscos e a resignação diante da morte no trabalho.

As formas de enfrentar a morte indicaram que a superação da perda foi viabilizada, em geral, por familiares, amigos e religião, elementos também encontrados no estudo de Moulin (2006) e que estão associados à coletividade. Embora haja semelhanças entre as pesquisas sobre essa questão, emergiram elementos novos no presente trabalho, mais voltados à esfera individual, como trabalho, estudo e psicoterapia. Os serviços de psicologia e pedagogia estiveram presentes no processo de superação das famílias das vítimas, incentivados pela empresa e pela escola.

Não foi possível analisar os efeitos psicossociais dos acidentes de trabalho fatais sem levar em consideração o contexto em que eles ocorreram, pois as relações estabelecidas com o trabalho interferem na atitude das famílias quanto ao fato e, além disso, contribuem, mesmo indiretamente, para que os acidentes continuem acontecendo, uma vez que nada é feito para evitá-los ou desvelar suas causas.

A análise do setor de rochas no Espírito Santo foi possibilitada pelos relatos das famílias, cujas vivências, atitudes e percepções sobre o trabalho no setor permitiram compreender como se constrói esse terreno cultural sobre trabalho e acidente, vida e morte. Observou-se que existe uma estreita relação entre esses acidentes e as condições de trabalho, como recorrência de acidentes no setor e condições de trabalho desfavoráveis à segurança. Essas características deram indícios de que os acidentes fatais estavam relacionados a esses elementos, que, mesmo não sendo associados ao acidente de trabalho pelas famílias, tal relação ficou evidente para o pesquisador, que não pode desconsiderar que a culpabilização do trabalhador é reforçada nessa situação.

É interessante observar que a percepção das famílias em relação à empresa não se modificou após a ocorrência do acidente. A família não "quer atrapalhar" a empresa, cujo patrão oferece trabalho e ajuda a ela. Acredita-se que essa atitude também contribui para que os acidentes não sejam investigados, pois a percepção dos familiares sobre o acidente está ligada à fatalidade e à visão do risco como inerente ao tipo de trabalho. Entender o risco dessa forma faz que não se vislumbre a possibilidade de transformação.

Quanto aos aspectos de suporte social, a maioria das empresas cumpriu suas obrigações legais com presteza, e, além disso, alguns empresários mostraram-se preocupados em acompanhar a situação das famílias. Levando em consideração o trabalho de Moulin (2006), as pessoas entrevistadas pela autora tiveram de recorrer a advogados e ao sindicato na busca de seus direitos, o que não prevaleceu entre as famílias entrevistadas na presente pesquisa. No entanto, não houve mudanças do ponto de vista da falta de informação, da análise dos acidentes e das alterações nos processo de trabalho visando sua prevenção.

Tanto na presente pesquisa quanto no estudo de Moulin (2006), observa-se o desejo de ser ajudado pelo patrão/amigo, indicando que a expectativa baseada nessa relação é muito forte, seja quando a empresa não ampara a família - realidade observada por Moulin -, seja quando a empresa se mostra solidária - realidade encontrada no estudo atual. Esta pesquisa evidenciou que as indenizações foram fundamentais para as famílias e, de fato, ajudaram em sua reorganização após o acidente.

Embora o Poder Público tenha sido importante para a reorganização familiar sob o ponto de vista econômico - em função dos benefícios concedidos -, mostrou-se falho quanto à consolidação de informações sobre os acidentes de trabalho, o que foi identificado no levantamento dos acidentes para realização desta pesquisa. Essa constatação alerta para a urgência de que a análise do acidente se torne relevante, pois, se o Poder Público desconhece as causas dos acidentes de trabalho e como eles ocorreram, não tem como atuar de forma preventiva, para promover mudanças na organização do trabalho com o intuito de evitar que 
novos acidentes ocorram. Além dessa questão prática, a falta de informação sobre o acidente produz concepções sobre a morte associadas a fatalidade e aos desígnios de Deus, o que, consequentemente, não leva em consideração a responsabilidade da organização do trabalho. Pensando que a resignação diante da morte por acidente de trabalho pode ser um fator que dificulta sua transformação, a pesquisa tem um efeito de contradiscurso, que vai de encontro à culpabilização do trabalhador e à forma hegemônica de análise de acidentes baseada no ato inseguro e na condição insegura.

Ao retratar o cenário e os desafios da saúde na década de 1990, Lacaz (1997) adverte "que se deve pensar na pauta de tarefas e embates quando se fala de políticas sociais no Brasil", mostrando que a saúde só se torna uma questão a partir do momento em que os trabalhadores têm força política para isso. Entende-se que o acidente de trabalho está submetido às mesmas circunstâncias descritas por Lacaz, que, no presente contexto, depende dos sindicatos, do Poder Público, da família, dos colegas de trabalho da vítima e também do que é produzido pela ciência para ter visibilidade social e força para promover mudanças. Dessa forma, espera-se que este estudo contribua para promover uma psicologia interessada no trabalho como possibilidade de se trabalhar e (sobre) viver com dignidade.

\section{Referências}

Ariès, P. (1989). Sobre a história da morte no ocidente desde a idade média (2ํㅡㄹ. ed.). Lisboa: Teorema.

Baptistini, M. A. (2009). Trabalhadores do setor de rochas ornamentais: vida, trabalho, saúde e acesso aos serviços de saúde. Dissertação de Mestrado, Programa de Pós-Graduação em Saúde Coletiva, Universidade Federal do Espírito Santo, Vitória.

Freitas, C. M. (2001). A análise de acidente de trabalho em indústrias tendo como referência a organização do trabalho. In L. H. Borges, M. G. B. Moulin \& M. D. Araújo (Orgs.), Organização do trabalho e saúde: múltiplas relações (pp. 87-108). Vitória: Editora EDUFES / CCHN.

Gomes, R. (2007). Análise e interpretação de dados de pesquisa qualitativa. In M. C. S. Minayo (Org.), Pesquisa social: teoria, método e criatividade (26⿳⺈⿴囗十一 ed., pp. 79-108). Petrópolis: Vozes.

Kovács, M. J. (1992). Morte e desenvolvimento humano (2ae ed.). São Paulo: Casa do Psicólogo.

Lacaz, F. A. C. (1997). Saúde dos trabalhadores: cenários e desafios. Cadernos de Saúde Pública, 13 (supl. 2), 7-19.

Laurell, A. C. \& Noriega, M. (1989). Processo de produção e saúde: trabalho e desgaste operário. São Paulo: Hucitec.

Mendes, R. \& Dias, E. C. (1991). Da medicina do trabalho à saúde do trabalhador. Revista de Saúde Pública, 25 (5), 341-349.

Minayo-Gomez, C. \& Thedim-Costa, S. M. F. (1997). A construção do campo da saúde do trabalhador: percurso e dilemas. Cadernos de Saúde Pública, 13 (supl. 2), 21-32.

Minayo, M. C. S. (2007). Pesquisa social: teoria, método e criatividade (26ํㅡㄹ. ed.) Petrópolis: Vozes.

Moulin, M. G. B. (2006). O lado não polido do mármore e granito: a produção social dos acidentes de trabalho e suas consequências no setor de rochas ornamentais no sul do Estado do Espírito Santo. Tese de Doutorado, Fundação Oswaldo Cruz, Escola Nacional de Saúde Pública Sérgio Arouca, Rio de Janeiro.

Oliveira, F. (2007). A persistência da noção de ato inseguro e a construção da culpa: os discursos sobre os acidentes de trabalho em uma indústria metalúrgica. Revista Brasileira de Saúde Ocupacional, 32 (115), 19-27.

Torres, W. C. (2002). O Conceito de morte em crianças portadoras de doenças crônicas. Psicologia: Teoria e Pesquisa, 18 (2), 221-229.

Endereço para correspondência:

anabeatryce@hotmail.com,mgbmoulin@gmail.com
Recebido em: 03/04/2012

Revisado em: 25/10/2012

Aprovado em: 29/10/2012 